Ambient Science, 2021: Vol. 08(Sp1); 40-44

DOI:10.21276/ambi.2021.08.sp1.0a05

\title{
A Study on Anthropometric and Performance Responses of Calisthenic Exercise Applications
}

\author{
Yağmur Yildiz' ${ }^{*}$ Hilal Kilinç Boz², Akan \\ Bayrakdar3 \\ ${ }^{1}$ Department of Sports and Health, Aksaray University, Aksaray, \\ Turkey \\ ${ }^{2}$ School of Physical Education and Sports, Van Yüzüncü Yil \\ University, Van, Turkey \\ ${ }^{3}$ School of Physical Education and Sports, Bingöl, Turkey \\ Study Area:Aksaray, Turkey \\ Coordinates: $38^{\circ} 22^{\prime} 27^{\prime \prime} \mathrm{N} 34^{\circ} \mathrm{O}^{\prime} 44^{\prime \prime} \mathrm{E}$
}

Key words: CE applications, Handball, BMI, Physical Exercise

\section{Abstract}

The KE was conducted for 30 minutes 3 days a week for 12 weeks. 25 boys were included in the study. 8 of these children did CE and handball training, 8 of them only did handball training. 9 people were not included in any exercise program and formed the control group. In our study, height, body weight, waist-hip ratio, body mass index (BMI), leg lift, plank, shuttle, push-up, vertical jump, standing long jump and 10-meter speed measurements were taken. The measurements taken were taken before the CE applications started and were taken again 12 weeks after the $\mathrm{CE}$ applications were terminated. In the in-group test results of $\mathrm{CE}$ and handball groups; body weight, BMI and waist-hip were observed and a significant difference was found. As a result of the intergroup test, significant differences were found in the variables of leg lift, plank, shuttle, push-up, vertical jump, standing long jump and 10 meters speed. According to the in-group test results of $\mathrm{CE}$ and handball groups; leg lift, plank, shuttle, push-up, vertical jump, standing long jump and 10-meter speed showed a significant difference. As a result, it is thought that Calisthenic exercise applications would increase performance and provide positive contributions to anthropometric properties in children athletegroups.

(Bayrakdar et al., 2018).

Since this type of exercise is known to be adapted to the physical fitness levels of individuals, it can be used in sedentary and elderly people without any problems (Akyol, 2014). Low to medium intensity $C E$ requires little equipment and is a type of program that can be maintained at home for a long time. It can be given as an exercise program at home or can be used as a part of physical education in schools (Tigli, 2017). CE, which is frequently preferred for the development of psychomotor skills such as balance, agility, and coordination, can also be beneficial in increasing muscle strength and aerobic capacity (Darwin et al., 2020). It also positively influences flexibility development (Thakur \& Vidhale, 2016).

Bodyweight exercises generally focus on working all your muscles and provide the highest level of neuromuscular efficiency (muscle-nerve connection). It is beneficial for different sports branches and fitness goals. CE is the safest form of exercise. Because it puts minimal pressure on the joints. They show a better effect than the best weight training with properly adjusted intensity and movements such as bending, swinging, and swinging 
frequency (Bozlak, 2019).

In many sports branches, from team sports to individual sports, athletes benefit from calisthenic exercises using their body weights to increase their performance. In line with all this information, this study was conducted to examine the anthropometric and performance responses of CE practices in child handball players.

\section{Materials and Methods:}

The athletes who actively participated in the handball competitions in Ankara and trained for more than 7 hours (4-5 units) weekly following the training plan and participated in one competition participated in the study. It was followed that the subjects did not have any disability that may affect the study during or before the study, by obtaining the consent of themselves, their parents, and coaches.

A total 25 handball players, ages 14-16, voluntarily participated in the study. The children participating in the study were divided into three groups. 8 of these children did calisthenic exercise and handball training, 8 of them did only handball training. 9 people were not included in any exercise program and formed the control group. The CE was conducted for 30 minutes 3 days a week for 12 weeks.

Anthropometric measurements are physical measurements of athletes' bodies and body parts (Preedy, 2012). Bodyweight, body mass index, and waist-hip measurements of swimming children were taken in our study.

Body Weiğht: the weight measurements of the subjects were made with a scale with an accuracy of \pm 100 gr. The measurement was taken in 'kg' while the subjects were wearing only shorts, in bare feet and anatomical standing position. Body mass indexes (BMI) were obtained by dividing the weight in kilograms by the square of the height in meters.

Body mass index (BMI): Body composition was calculated with the formula kg / height2 (Cole et al., 2007). Body mass index is a method used to assess the risk of health problems at the population level. It was developed by Adolphe Quetelet in 1970 based on the data and reports of 7 different countries.

Waist/ Hip Ratio: Waist and hip circumferences were measured in $\mathrm{cm}$ with a tape measure. Waist circumference measurement was made so that the tape measure passed through the umbilicus level. Hip circumference was measured by placing the tape measure through the widest part of the hips. The waist-hip ratio was calculated by dividing the measured values (ACSM, 2013).

\section{Performance Measurements}

Leğ Raise: participants were asked to raise their legs 5-10 $\mathrm{cm}$ high and keep them straight while lying with their backs to the mat. The hands were kept under the body between the back and the hips during the movement, thus reducing the load on the back muscles, increasing the load on the abdominal muscles. The test was terminated if the subjects significantly disturbed their body position and/or touched their legs on the ground. The measurement was made with a stopwatch and the scores were recorded in seconds (Parkhouse \& Ball, 2011).

Planks: the subjects are in the prone position, the elbows and forearms are shoulder-width apart, the roots of their toes touch the ground and pushes the ground, the pelvis is high above the ground, the hip and abdominal muscles are active, the spine is in its natural position, the head is in its natural position, and the body has formed a line close to the parallel. After the beginning of the period, the time until the subject was tired without breaking the stabilization rules was recorded in seconds (Barwick et al., 2012).

Sit-ups: subjects were asked to lie on the ground in a supine position with their knees bent at a right angle (Esco et al., 2008). The soles of the feet were placed on the floor and the subjects' arms were extended to the side (hands extended to the side of the heels during movement).

Push-ups: subjects were asked to do as many push-ups as possible within 6o seconds (Norton \& Olds, 1996). The participants took position by maintaining the natural position of the spine, with hands shoulder widths approximately 0.10-0.20 meters, knees not touching the ground, legs straight.

Vertical Jump: the distance from which the subject stretches his hand to the wall without raising rhymes is marked. He then jumped parallel to the wall to the highest point he could jump. The difference between reach and jump distance was calculated and recorded (Kumartasli et al., 2014).

Lonğ Jump with a Stand: standing with the feet together and the toes behind the jump line. The knees were bent and both arms were thrown back as far as possible (Kumartasli et al., 2014).

10-meter speed: the velocity measurements of the subjects were measured on a flat surface and the length of the running area was determined as $10 \mathrm{~m}$.

Training Plan: at the beginning of each training unit, the athletes were given warm-up exercises to increase body temperature and blood circulation, and the risks associated with a spinal injury and lower back pain were tried to be eliminated by providing stretching and stretching of the muscles, especially those involving the lumbopelvic region. As the adaptation of the athletes is achieved, the gradual loading in the context of the principle of increasing load for subsequent adaptations (Müniroglu \& Deliceoglu, 2008); variables such as exercise intensity, duration, the number of repetitions, and scopewere increased by playing. 
Before and after the application of the 8-week calisthenic training program, a calisthenic training program consisting of movements selected in accordance with the movement classification was applied to the control group in calisthenic exercise programming (Jeffreys, 2002; Brookbush, 2011).

The exercises included in the calisthenic training program were selected according to 4 basic features. Plank versions were used for stabilization of the spine, crunch versions for flexion of the spine, bridge versions for hip activation and pelvic stabilization, and oblique crunch versions for rotation of the spine and hip (Brookbush, 2011). In versions of static core exercises such as planks and bridge movements, the duration; whereas in the versions of dynamic core exercises such as crunch and oblique crunch, number limitations are introduced. According to the principle of the increasing load, as time progresses, the versions of the movements have become more difficult, and the number of times and repetitions has been increased (Bompa \& Haff, 2009).

The analysis of the obtained data was made in the SPSS 23 package program. The distributions of the variables in the first posttest were examined according to the groups, the normality of the distributions, and the homogeneity of the variances was determined by Mauchly's Sphericity Test and Levene test. Analyzes of intergroup, intragroup, and the effect of training were performed with repeated measurements using multi-directional variance analysis (MANOVA). The Bonferroni test was continued for Post Hoc comparisons in significant relationships, and the significance level was accepted as 0.05 .

Results:

Table-1: Investigation of Anthropometric response

\begin{tabular}{ccccl}
\hline $\begin{array}{l}\text { Variables } \\
\text { Group }\end{array}$ & $\mathrm{N}$ & Pre test $^{1}$ & Post test $^{1}$ & Int-gr.Ch.(\%) \\
\hline Body Weight $(\mathrm{kg})$ & $(\mathrm{F}=0.678 ; \mathrm{p}>0.518)$ & & \\
CE \& H-ball & 8 & $44.87 \pm 5.98$ & $45.72 \pm 6.32$ & $0.85(1.89)^{*}$ \\
Handball & 8 & $40.12 \pm 8.45$ & $40.40 \pm 7.19$ & $0.28(0.69)$ \\
Control & 9 & $45.11 \pm 5.46$ & $45.46 \pm 5.56$ & $0.35(0.77)$ \\
BMI (kg/height $\left.{ }^{2}\right)$ & $(\mathrm{F}=0.681 ; \mathrm{p}>0.516)$ & & \\
CE \& H-ball & 8 & $19.87 \pm 2.21$ & $20.24 \pm 2.36$ & $0.37(1.86)^{*}$ \\
Handball & 8 & $17.34 \pm 3.02$ & $17.47 \pm 2.48$ & $0.13(0.74)$ \\
Control & 9 & $19.45 \pm 1.89$ & $19.60 \pm 1.83$ & $0.15(0.77)$ \\
Waist-Hip Ratio (Waist/hip) $\left(\mathrm{F}=8.993^{* *} ; \mathrm{p}<0.001\right)$ & \\
CE \& H-ball & 8 & $0.910 \pm .057$ & $0.922 \pm .055$ & $0.012(1.31)^{*}$ \\
Handball & 8 & $0.963 \pm .099$ & $0.956 \pm .095$ & $0.007(0.72)$ \\
Control & 9 & $0.899 \pm .049$ & $0.900 \pm .056$ & $0.001(0.11)$ \\
\hline
\end{tabular}

As a result of the comparisons between the groups in the table, no significant difference was found in body weight and BMI values. However, a significant difference at $\mathrm{p}<0.05$ level was found in the waist-hip ratio. According to the in-group * test results of KE and Handball groups; body weight $1.89 \%$, BMI 1.86\% and waist-hip 1.31\% were observed and a significant difference was found at $\mathrm{p}<0.05$ level. No significant difference was found in the within-group * test results in handball and control groups.

Table-2 : Examination of performance responses

\begin{tabular}{|c|c|c|c|c|}
\hline \multirow{2}{*}{$\begin{array}{r}\text { Variables } \\
\text { Group }\end{array}$} & \multicolumn{2}{|c|}{$(\mathrm{F} ; \mathrm{P})$} & \multirow[b]{2}{*}{ Post test $^{1}$} & \multirow[b]{2}{*}{ Int-gr.Ch.(\%) } \\
\hline & $\mathrm{N}$ & Pre test $^{1}$ & & \\
\hline Leg Raise (sec) & \multicolumn{4}{|c|}{$\left(\mathrm{F}=6.674^{* *} ; \mathrm{P}<0.005\right)$} \\
\hline CE \& H-ball & 8 & $37.25 \pm 18.37$ & $39.66 \pm 19.47$ & $2.41(6.46)^{*}$ \\
\hline Handball & 8 & $29.05 \pm 13.21$ & $30.65 \pm 12.73$ & $1.6(5.50)^{*}$ \\
\hline Control & 9 & $33.94 \pm 6.30$ & $34.04 \pm 6.53$ & $0.1(0.29)$ \\
\hline Plank (sec) & \multicolumn{4}{|c|}{$\left(\mathrm{F}=6.463^{* *} ; \mathrm{P}<0.006\right)$} \\
\hline CE \& H-ball & 8 & $44.37 \pm 17.03$ & $46.25 \pm 17.13$ & $1.88(4.23)^{*}$ \\
\hline Handball & 8 & $41.50 \pm 5.68$ & $43.00 \pm 5 \cdot 70$ & $1.5(3.61)^{*}$ \\
\hline Control & 9 & $33.22 \pm 8.05$ & $34.00 \pm 8.72$ & $0.78(2.34)$ \\
\hline Sit ups (1 min) & \multicolumn{4}{|c|}{$\left(\mathrm{F}=22.613^{* * *} ; \mathrm{P}<0.000\right)$} \\
\hline CE \& H-ball & 8 & $11.87 \pm 9.07$ & $15.25 \pm 9 \cdot 30$ & $3.38(11.47)^{*}$ \\
\hline Handball & 8 & $11.75 \pm 2.91$ & $12.62 \pm 3.11$ & $0.87(7.40)^{*}$ \\
\hline Control & 9 & $12.66 \pm 2.78$ & $12.88 \pm 2.93$ & $0.22(1.73)$ \\
\hline Push ups (1 min & \multicolumn{4}{|c|}{$\left(\mathrm{F}=5.388^{*} ; \mathrm{P}<0.012\right)$} \\
\hline CE \& H-ball & 8 & $11.12 \pm 9.07$ & $13.25 \pm 8.79$ & $2.13(19.15)^{*}$ \\
\hline Handball & 8 & $12.12 \pm 7.12$ & $14.25 \pm 7.57$ & $2.13(17.57)^{*}$ \\
\hline Control & 9 & $11.66 \pm 3 \cdot 31$ & $12.00 \pm 3.87$ & $0.34(2.91)$ \\
\hline \multicolumn{5}{|c|}{ Vertical Leap $(\mathrm{cm})\left(\mathrm{F}=5.656^{*} ; \mathrm{P}<0.010\right)$} \\
\hline CE \& H-ball & 8 & $23.37 \pm 5 \cdot 55$ & $26.00 \pm 4.95$ & $2.63(11.25)^{*}$ \\
\hline Handball & 8 & $24.87 \pm 3.75$ & $27 \cdot 50 \pm 3 \cdot 50$ & $2.63(10.57)^{*}$ \\
\hline Control & 9 & $25.44 \pm 4.50$ & $26.00 \pm 4.87$ & $0.56(2.20)$ \\
\hline \multicolumn{3}{|c|}{ Standing long jump (cm) } & \multicolumn{2}{|c|}{$\left(\mathrm{F}=23.225^{* * *} ; \mathrm{P}<0.000\right)$} \\
\hline CE \& H-ball & 8 & $1.42 \pm 0.15$ & $1.51 \pm 0.15$ & $0.09(6.33)^{*}$ \\
\hline Handball & 8 & $1.44 \pm 0.22$ & $1.47 \pm 0.22$ & $0.03(2.08)^{*}$ \\
\hline Control & 9 & $1.33 \pm 0.09$ & $1.32 \pm 0.10$ & $0.01(0.75)$ \\
\hline 10 meter speed & & $\left(\mathrm{F}=6.697^{* *} ;\right.$ & $\mathrm{P}<0.005)$ & \\
\hline CE \& H-ball & 8 & $2.36 \pm 0.20$ & $2.31 \pm 0.21$ & $0.05(2.11)^{*}$ \\
\hline Handball & 8 & $2.37 \pm 0.25$ & $2.35 \pm 0.20$ & $0.02(0.84)^{*}$ \\
\hline Control & 9 & $2.33 \pm 0.24$ & $2.34 \pm 0.22$ & $0.01(0.42)$ \\
\hline
\end{tabular}

CE \& H-ball= CE \& Handball; Int-gr.Ch.(\%)= Intra-group change (\%)

In the table, significant differences were found at the level of $\mathrm{p}<0.05$ in the variables of leg lift, plank, shuttle, push-up, vertical jump, standing long jump and 10-meter speed as a result of the intergroup * test. According to the in-group * test results of CE and Handball group; leg lift, plank, shuttle, push-up, vertical jump, standing long jump and 10-meter speed and a significant difference was found at the $\mathrm{p}<0.05$ level. According to the in-group * test results of the handball group; leg raising, plank, shuttle, push-up, vertical jump, standing long jump and 10 meters speed and a significant difference was found at the $\mathrm{p}<0.05$ level. No significant difference was found in the within-group * test results of the control group.

\section{Discussion:}

This study aims to examine the anthropometric and performance responses of calisthenic exercise (CE) applications in child handball players. Calisthenic exercises are a group of various exercises. These exercises are short muscle contractions using bodyweight combined with movement to increase body strength and flexibility and involve all body movements, thus requiring contraction of 
large muscle groups. Calisthenic exercises focus on large muscles and can be combined rhythmically with breathing exercises (Aydin et al., 2014). It has been proven that calisthenic exercises increase the human mind and physical performance.

For this reason, they are non-formal education regimens used in both rehabilitation and sports education. In fact, various central and peripheral effects of calisthenic exercise in different populations have been discussed in the literature (Kaya et al., 2012).

As a result of the comparisons between the groups participating in our study, no significant difference was found in body weight and BMI values. However, a significant difference at $\mathrm{p}<0.05$ level was found in the waist-hip ratio. According to the in-group * test results of CE and Handball group; Bodyweight 1.89\%, BMI 1.86\%, and waist-hip 1.31\% were observed, and a significant difference was found at $\mathrm{p}$ $<0.05$ level. In the handball and control groups, there was no significant difference in the within-group * test results. In our study, significant differences were found at $\mathrm{p}<0.05$ in the variables of leg lift, plank, shuttle, push-up, vertical jump, standing long jump, and 10-meter speed as a result of the intergroup * test. According to the in-group * test results of CE and Handball group; leg lift 6.46\%, plank, 4.23\%, shuttle $11.47 \%$, push-up $19.15 \%$, vertical jump $11.25 \%$, standing long jump $6.33 \%$ and 10 -meter speed $2.11 \%$ and a significant difference was found at the $\mathrm{p}<0.05$ level. According to the in-group * test results of the handball group; leg raising $5.50 \%$, plank, $3.61 \%$, shuttle $7.40 \%$, pushup $17.57 \%$, vertical jump $10.57 \%$, standing long jump $2.08 \%$ and 10 meters speed $0.84 \%$ and a significant difference was found at the $\mathrm{p}<0.05$ level. There was no significant difference in the in-group * test results of the control group.

A study with healthyyoung adults looked at the effects of 8 weeks of calisthenic exercises on static balance; There was no significant increase in the scores of standing on one leg with eyes closed (Aslan \& Livanelioglu, 2003). In a study conducted on sedentary women diagnosed with upper extremity and low back pain, 8o individuals were randomly divided into 2 groups. Clinical treatment (tens therapy, ultrasound, hot pack) was applied to the control group of 40 people, and the second group applied for a calisthenic exercise program with the help of a physiotherapist 3 days a week for 8 weeks in addition to the clinical treatment.

At the end of the application, a decrease in waist/hip ratio and pain intensity values of calisthenic exercises applied with clinical treatment were detected, whereas pain threshold value, muscle strength, and flexibility values increased (Akyol, 2014). In the study conducted by Iwamoto et al., 2009 on two experimental groups consisting of 34 people, they found that body balance, flexibility, walking ability, and muscle strength increased significantly in the exercise group after calisthenic exercise applied to the subjects 3 days a week for 5 months compared to the control group.

According to the results of their balance test, they achieved a significant increase in the balance values of the exercise group in the right and left directions, but they did not show a similar difference between the groups in the anterior direction (Iwamoto et al., 2009). In a study conducted with middle-aged sedentary women, the effects of 12-week calisthenic studies on body weight, body fat percentage, resting heart rate, blood pressure, flexibility, endurance, and strength values were examined; As a result of the study, significant increases in body weight, body fat percentage, resting heart rate, systolic and diastolic blood pressures, strength, flexibility, and endurance were found in the experimental group (Dönmez \& Aydos, 200o). While studies are supporting that calisthenic and pilates exercises do not change body weight and body mass index (Segal et al., 2004; Baylan, 2008), regular pilates and aerobic exercises reduce body weight and body mass index (Karacan\& Çolakoglu, 2003; Arslan et al., 2012; Özdemir, 2014), there are also studies reporting something else. Erbas (2007) applied calisthenic exercises with aerobic content for 6 months, 3 days a week, and 50 minutes to examine the effects of calisthenic exercises on physical and physiological parameters for middle-aged obese women and showed a significant difference in flexibility, sit-ups, push-ups, right and left-hand grip strength of the subjects has determined an increase.

Conclusively, it can be said that regular application of calisthenic exercises according to the principle of continuity, three times a week, 30 minutes in each training unit, for 12 weeks or more, will provide benefits in terms of health and performance. Also, it is thought that providing a variety of training modes (skipping rope, elastic bands, step, health balls) in applications over time will provide benefits in terms of applications.

\section{References:}

Akyol, B. (2014): The effect of calisthenic exercises on muscle strength, flexibility, pain intensity and body mass index in sedentary women with low back pain. J. Inönü Uni. Health Ser. Voca. School, 2 (2):29-39.

Akyol, B., Arslan, C. \& Çolak, C. (2016): The effect of callisthenic exercises on pain threshold, pain severity and muscle strength on sedentary women diagnosed with upper extremity and low back pain. L. Turgut Ozal Med. Cen., 23(1):29-35.

American College of Sports Medicine. (2013): ACSM's ğuidelines for exercise testing and prescription. Pub. by: Williams \& Wilkins, Lippincott.

Arslan, F., Çakmakçi, E., Taşgın, H., Çakmakçi, O. \& Ismet, C.G. (2012): Evaluation of effects of pilates mat exercise program on weight loss and physical fitness parameters in middle aged perimenopausal sedentary women. J.Phy. Edu. Sport Sci.,6(1).

Aslan, U.B. \& Livanelioğlu, A. (2003): Effects of hatha yoga and calisthenic exercises on static balance. J. Sport Sci., 14(2):8391. 


\section{ORIGINAL ARTICLE}

Aydin, T., Akif Sariyildiz, M., Guler, M., Celebi, A., Seyithanoglu, H., Mirzayev, I., Peru, C., Sezer, E.\& Batmaz, I. (2014): Evaluation of the effectiveness of home based or hospital based calisthenic exercises in patients with multiple sclerosis. Eu. Rev. Med. Pharmacol. Sci., 18(8):1189-1198.

Barwick, R.B., Tillman, M.D., Stopka, C.B., Dipnarine, K., Delisle, A. \& Sayedul, M.H. (2012): Physical capacity and functional abilities improve in young adults with intellectual disabilities after functional training. J. Streng. Cond. Res., 26:1638-1643.

Baylan, N. (2008):The Effect of Pilates Exercise on Basal Metabolism and Body Composition in Different Age Groups. Master's Thesis, Institute of Health Sciences, Marmara University.

Bayrakdar, A. (2018): The Effect of Calisthenic Exercises Performed on Stable and Unstable Grounds on Balance in Swimming Children. Doctoral Thesis. Gazi University Institute of Health Sciences.Ankara.

Bayrakdar, A., Demirhan, B. \& Zorba, E. (2019): The effect of calisthenics exercises of performed on stable and unstable ground on body fat percentage and performance in swimmers. MANAS Sosyal Aras, tirmalar Dergisi, 8(3):29792992.

Bompa, T.O.\& Haff, G.G. (2009): Periodization: Theory and methodology of training. Pub. by: Human Kinetics Publishers, Canada.

Bozlak, S. (2019): Investigation of the Effect of Calisthenic Exercises Applied to Sayokan Athletes on Flexibility, Strength and Balance Abilities. Master Thesis. Kırıkkale University Institute of Health Sciences. Kırıkkale.

Brookbush, B. (2011): Fitness or Fiction, the truth about diet and exercise. Pub. by: Brent Brookbush, Los Angeles.

Çeçen, S. \& Bulur, Ş. (2015): General Principles of Preparing Exercise Prescriptions. J. Tur. Fam. Phys., 6(1):40-46.

Cole, T.J., Flegal, K.M., Nicholls, D. \& Jackson, A.A. (2007): Body mass index cut offs to define thinness in children and adolescents: international survey. BMJ, 335(7612):194.

Darwin, R.E.\& Singh, J.P.J. (2020): Impact of calisthenýcsexercýse on selected physýcalvarýables among school students of slum. Juni Khyat J., 10(5).

Doğan, Y. (2020): Effects of regular exercise on respiratory function parameters in 10-12 year old children. Master Thesis, İnönü University Institute of Health Sciences).

DÖNMEZ, G. \& Aydos, L. (200o):The effect of calisthenic studies on physiological and physical parameters of middle aged sedentary women. GaziJ.Phy. Edu. Sport Sci., 5(2):17-25.

Engels, H.J., Currie, J.S., Lueck, C.C. \& Wirth, J.C. (2002): Bench/step training with and without extremity loading: Effect on muscular fitness, body composition profile, and psychological affect. J. Sport. Med.Phy. Fit., 42(1):71-78.

Erbaş, Ü. (2007): Physical and Physiological Effects of Calisthenic Exercises for Middle Age Obese Women. Gazi University, Institute of Health

Sciences, Department of Physical Education and Sports, M.Sc. Thesis, Ankara: Gazi University

Esco, M.R., Olson, M.S. \& Williford, H. (2008): Relationship of push-ups and sit-ups tests to selected anthropometric variables and performance results: A multiple regression study.J. of Streng. Conditi. Res., 22:1862-1868.
Ambient Science, 2021: Vol. 08(Sp1); 40-44 DOI:10.21276/ambi.2021.08.sp1.oa05

Genç, H. (2020): Effect of the calisthenics exercises on static and dynamic balance in tennis players. Int. J. Appl. Exer. Physiol., 9(3):2322-3537.

Iwamoto, J., Suzuki, H., Tanaka, K., Kumakubo, T., Hirabayashi, H., Miyazaki, Y., Sato, Y., Takeda, T.\& Matsumoto, H. (2009): Preventative effect of exercise against falls in the elderly: a randomized controlled trial. Osteopor. Int., 20(7):1233-1240.

Jeffreys, I. (2002): Developing a progressive core stability program. Streng. Cond. J., 24(5):65-6.

Karacan, S. \& Çolakoğlu, F.F. (2003): The effect of aerobic exercise on body composition and blood lipids in sedentary middle age women and young women. Spormeter J. Phy. Edu. Sport Sci., $1(2): 83-88$.

Kaya, D.O., Duzgun, I., Baltaci, G., Karacan, S. \& Colakoglu, F. (2012): Effects of calisthenics and pilates exercises on coordination and proprioception in adult women: a randomized controlled trial. J. Sport Rehabil., 21(3):235-243.

Kumartaşli, M., Topuz, R. \& Dağdelen, S. (2014):Evaluation of the motoric performance of 10-12 age group football players. Int. J. Sport Cul.Sci., 2(2):101-113.

Kurt, S., Hazar, S., İbiş, S., Albay, B. \& Kurt, Y. (2010):Evaluation of the effects of eight-week step-aerobic exercise on some physical fitness parameters in middle aged sedentary women. Int. J. Human Sci., 7(1):665-674.

Müniroğlu, S. \& Deliceoğlu, G. (2008):Competition analysis and observation techniques in football. Pub. by: Ankara University Press, Ankara.

Norton, K., \& Olds, T. (Eds.). (1996): Anthropometrica:A Textbook of Body Measurement for Sports and Health Courses. Pub. by: UNSW press. Sydney:Australia's Global University.

Noyan, A.Y. \& Fizyoloji, H. (1998): Ağrý Duyularý. Pub. by: Meteksan, Ankara.

Özdemir, İ. (2014): Effects of aerobic-step and pilates exercises on body composition, blood lipids and blood sugar in middle age women. Doctoral dissertation, Selcuk University Institute of Health Sciences.

Parkhouse, K.L.\& Ball, N. (2011): Influence of dynamic versus static core exercises on performance in field-based fitness tests. $L$. Bodywork Move. Ther., 15(4):517-524.

Preedy, V.R. (2012): Handbook of Anthropometry: Physical Measures of Human form in Health and Disease. Pub. by: Springer Science \& Business Media.

Segal, N.A., Hein, J. \& Basford, J.R. (2004): The effects of pilates training on flexibility and body composition: an observational study. Arc. Phy. Med. Rehabil., 85(12):1977-1981.

Srivastava, R.(2016): Impact of yogasanascalisthenýc and combined exercise on selected physical variable of school boys. Bhartiya Bhasha, Shiksha, Sahitya Evam Shodh, 7: (online).

Thakur, R. \& Vidhale, S.G. (2016): Effect of calisthenics and noncalisthenics exercises on physical fitness. Int. J. Phy. Edu. Sports Appl. Sci., 6(2):1-7.

Tiğli, A. (2017):The effect of calisthenic exercise program on inflammatory markers and quality of life after renal transplantation. Doctoral Thesis. Hacettepe University Institute of Health Sciences.Ankara. 